\title{
CORRECTION
}

\section{Dramatic rebounds of MS during pregnancy following fingolimod}

withdrawal

Neurol Neuroimmunol Neuroinflamm 2018;5:e462. doi:10.1212/NXI.0000000000000462

In the Clinical/Scientific Note "Dramatic rebounds of MS during pregnancy following fingolimod withdrawal" by G. Novi et al., ${ }^{1}$ there is an error in the study funding statement, which should have specified, "Some of the results discussed in this publication were supported by Compagnia di San Paolo." The authors regret the omission.

\section{Reference}

1. Novi G, Ghezzi A, Pizzorno M, et al. Dramatic rebounds of MS during pregnancy following fingolimod withdrawal. Neurol Neuroimmunol Neuroinflamm 2017;4:e377. 


\section{Neurology \\ Neuroimmunology \& Neuroinflammation}

\section{Dramatic rebounds of MS during pregnancy following fingolimod withdrawal Neurol Neuroimmunol Neuroinflamm 2018;5; \\ DOI 10.1212/NXI.0000000000000462}

This information is current as of April 12, 2018

\section{Updated Information \& \\ Services}

References

Permissions \& Licensing

Reprints including high resolution figures, can be found at:

http://nn.neurology.org/content/5/3/e462.full.html

This article cites 1 articles, 0 of which you can access for free at: http://nn.neurology.org/content/5/3/e462.full.html\#\#ref-list-1

Information about reproducing this article in parts (figures,tables) or in its entirety can be found online at:

http://nn.neurology.org/misc/about.xhtml\#permissions

Information about ordering reprints can be found online: http://nn.neurology.org/misc/addir.xhtml\#reprintsus

Neurol Neuroimmunol Neuroinflamm is an official journal of the American Academy of Neurology.

Published since April 2014, it is an open-access, online-only, continuous publication journal. Copyright $(\subseteq$ 2018 American Academy of Neurology. All rights reserved. Online ISSN: 2332-7812.

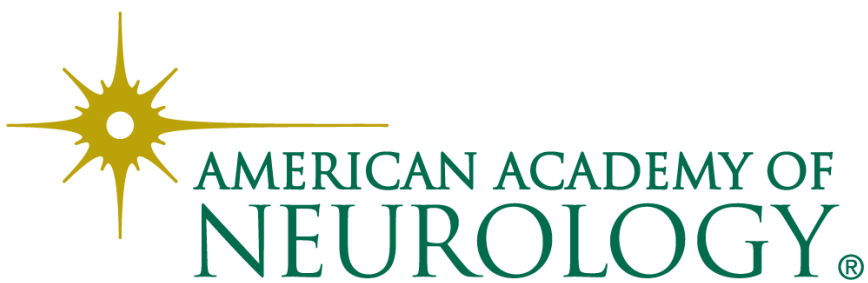

